\title{
Human studies on probiotics: Aspects of scientific documentation
}

\author{
By Seppo Salminen
}

\begin{abstract}
The assessment of probiotic health effects has to be based on human studies. Knowledge of the mechanisms is an important factor, complemented with target functions and biomarkers that are accepted as relevant to the state of health and well-being or reduction in risk of disease. Human studies should preferably be conducted by at least two independent research groups in different locations. In conclusion, well-designed human studies with requirements similar to those for pharmaceutical studies are required to demonstrate health benefits. Additionally, epidemiological studies or post-marketing surveillance can be recommended to assess both safety and efficacy of probiotics. Using these criteria, only a few health-promoting effects can be considered scientifically proven for specific strains. These include effects upon rotavirus diarrhoea, antibiotitic-associated diarrhoea and alleviation of lactose intolerance symptoms. The reported effects are strain-specific and product-specific. As more information is accumulating the evidence may be soon obtained for other health effects.

Key words: Clinical studies, health effects, probiotics
\end{abstract}

\section{Introduction}

The recent definition of a probiotic is based on the ILSI Europe (International Life Sciences Institute Europe within the project Functional Food Science in Europe, (FUFOSE), working group on functional foods. Probiotics are "viable microbial food supplements which beneficially influence the health of humans" (1). Many probiotics are normal commensal bacteria of the healthy human gut microflora, and the most frequently used probiotics include the genera lactobacilli and bifidobacteria. The definition of probiotics requires the safety and efficacy of probiotics to be scientifically demonstrated for each strain and each product. Demonstration of health effects consists of research on mechanisms and clinical and nutritional studies with human subjects.

The same ILSI Europe working group also defined probiotic foods as functional if they have been satisfactorily demonstrated to beneficially affect one or more target functions in the body beyond adequate nutritional effects, in a way that is relevant to either an improved state of health and well-being and/or reduction in the risk of diseases $(1,2)$. These definitions have set the basis for the assessment of the health effects of probiotics. It can be concluded that specific probiotics have proven benefits that can be attributed to specific products. At present, data has accumulated to prove that a few probiotic effects can be considered scientifically demonstrated in human studies.

The aim of this presentation is to summarise the current status of probiotic studies in human subjects and to assess the scientific proof of probiotic effects.

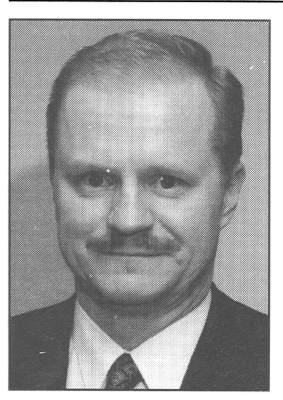

Seppo Salminen, Prof., Degree programme on Health Sciences, University of Turku, Turku, Finland and Visiting Prof., Key Centre of Applied and Nutritional Toxicology, RMIT University, Melbourne, Vic, Australia. E-mail: sepsal@utu.fi

The article is based on a lecture presented at the symposium "Probiotics and prebiotics - scientific evidence in humans as a basis for health claims", 1415 November 2000, arranged by SNF Swedish Nutrition Foundation.

\section{Assessment of probiotic strains - their health effects}

All currently used probiotic strains are unique and their uniqueness depends on the scientifically proven effects. Each probiotic strain is different and thus the strain properties and characteristics should be well defined using up-to-date method. Due to the strain differences, studies on even closely related strains cannot be extrapolated without great caution. It is important to clearly identify each strain using modern methodology and also to make all study strains available for all research groups participating in the worldwide assessment work on health effects and mechanisms. The strain properties also set new quality control criteria for the food and nutritional product industry, as the clinical studies are only valid for the strains with the set criteria (3). It is most important that each commercially used strain is deposited in a public culture collection and the strain properties are compared with the original deposited strain properties.

The assessment of the health-promoting potential of a probiotic has to be based on a valid scientific hypothesis and realistic studies supporting the hypothesis. Such an approach has been suggested also by the ILSI Europe working group $(1,2,4)$. Understanding the mechanisms is an important factor, complemented with reported effects in target functions and biomarkers that are accepted as relevant to the state of health and well-being or reduction of risk of disease. The hypothesis can be further supported by studies carried out in vitro using cell culture models or in vivo using animal models $(1,2)$. However, the most important studies are carefully planned and monitored clinical studies in human subjects. All available data has to be assessed with reference to studies in human subjects, preferably conducted by at least two independent research groups in different locations. Multicentre studies offer an excellent oppurtunity for the assessment health effects in humans. In summary, welldesigned human studies with requirements similar to those for pharmaceutical studies are required to demonstrate health benefits. Epidemiological studies or post-marketing surveillance are recommended to further assess both the safety and efficacy of probiotics. Using these criteria, a few health-promoting effects can be considered scientifically proven for specific strains. The methodological aspects of studies used for 
assessment of health effects have been reviewed by Rossander (5), De Roos and Katan (6) and Pathmakanthan et al. (7) These reviews provide the discussion on with nutritional study guidelines which can be applied for probiotic studies. The available studies and important findings on the health effects are reviewed as follows. As a large number of up-to-date studies can be found, recent reviews are included as extensive key sources of detailed references in this area.

\section{Well-characterised probiotic strains and their health effects}

The strains that have been characterised for their clinical effects and properties have been assessed in recent reviews $(1,6,8,9)$. A number of health-related effects have been suggested and are partially established, but some can be considered reasonably well established and clinically well documented. Such strainspecific proven health effects are listed in Table 1. Other effects reported for specific probiotic strains are included in Table 2.

\section{Scientifically proven effects}

\section{Lactose intolerance}

There is a large body of convincing evidence from several studies that lactose-intolerant individuals suffer fewer symptoms if milk in the diet is replaced with fermented dairy products. The reduced levels of lactose in fermented products, due to partial hydrolysis of lactose during fermentation, may contribute to the greater tolerance of fermented dairy products in human studies $(1,9,10)$. However, most studies are difficult to assess as no indication is given of the specific yoghurt strain, its lactase activity, or the lactose content of the test product. Most data is available on recent human studies, many of them double-blinded and placebo-controlled. However, the lactase activities of the strains in the products is still largely missing as are the strain sources and specifications $(9,10)$.

The mechanisms of action or probiotics and lactic acid bacteria include the following: lower lactose concentration in the
Table 1. Established and proposed health effects of probiotics.

Scientifically established effects

Alleviation of the symptoms of lactose intolerance

Reduction of the duration of rotavirus diarrhoea

Prevention of rotavirus diarrhoea

Reduction of the duration of antibiotic associated diarrhoea,

Future challenges for human studies

Treatment and prevention of food allergy

Reduction in the recurrence of superficial bladder cancer

Reduction in the risk of colon cancer

Treatment of irritable bowel disease and irritable bowel syndrome,

Crohn's disease Clostridium difficile diarrhoea , cholesterol control

Inhibition of intestinal pathogens, including Helicobacter pylori

fermented product, high lactase activity of bacterial preparations used in the production, and increased active lactase enzyme entering the small intestine with the fermented product or within the viable bacteria able to survive gastric and bile conditions. The bacterial enzyme, $\beta$-galactosidase, which can be detected in the duodenum and terminal ileum after consumption of viable yoghurt, is thought to be the major factor that improves digestibility by the hydrolysis of lactose, mainly in the terminal ileum. Other factors suggested to influence lactose digestion include the slower gastric emptying and intestinal transit of semi-solid milk products such as yoghurt $(9,10)$. These may influence and modify the intestinal microflora to better tolerate or utilise lactose.

As great strain differences in the ability of even common lactic acid bacteria to utilise lactose have been reported, studies on specific strain and products are most important. Some probiotic strains are not able to utilise lactose as their substrate influencing both the levels of lactose in the final product and the degradation of lactose in the gastrointestinal tract. It is therefore important to conduct studies on final products and relate the results to the lactose content in the product and the $\beta$-galactosidase activity in the viable or non-viable bacterial cells potentially entering the

Table 2. Current probiotic bacteria and their reported effects. Selected key references and reviews with further references.

\begin{tabular}{|c|c|c|}
\hline Strain & Reported effects in clinical studies & Ref. \\
\hline L. johnsonii LA1 & $\begin{array}{l}\text { Adherence to human intestinal cells, balances intestinal microflora, } \\
\text { immune enhancement, adjuvant in } H \text {. pylori treatment }\end{array}$ & $1,8,9,20,21,34$ \\
\hline $\begin{array}{l}\text { L. acidophilus } \\
\text { NCFB } 1748\end{array}$ & $\begin{array}{l}\text { Lowering of faecal enzyme activity, decreasing faecal mutagenicity, } \\
\text { prevention of radiotherapy-related diarrhea, improvement of constipation }\end{array}$ & $1,8,9$ \\
\hline $\begin{array}{l}\text { L. rhamnosus GG } \\
\text { (ATCC 53013) }\end{array}$ & $\begin{array}{l}\text { Treatment and prevention of rotavirus diarrhea. Prevention of } \\
\text { antibiotic-associated diarrhoea, Treatment of food allergy in infants. } \\
\text { Treatment of relapsing } C \text {. difficile diarrhoea }\end{array}$ & $\begin{array}{l}6,8,9,12-14,17 \\
21-26\end{array}$ \\
\hline L. acidophilus NFCM & $\begin{array}{l}\text { Lowering of faecal enzyme activity, high lactase activity, treatment of } \\
\text { lactose intolerance, production of bacteriocins }\end{array}$ & 9,10 \\
\hline L. casei Shirota & $\begin{array}{l}\text { Prevention of intestinal disturbances, balancing intestinal bacteria, } \\
\text { lowering faecal enzyme activities, positive effects on reducing } \\
\text { the recurrence of superficial bladder cancer. }\end{array}$ & $1,8,9,20,21,29-31$ \\
\hline $\begin{array}{l}\text { S. thermophilus; } \\
\text { L. bulgaricus }\end{array}$ & $\begin{array}{l}\text { No effect on rotavirus diarrhea, no immune enhancing effect during } \\
\text { rotavirus diarrhea, no effect on faecal enzymes, strain dependent } \\
\text { improvement of lactose intolerance symptoms. }\end{array}$ & 9,11 \\
\hline L. acidophilus La-5 & $\begin{array}{l}\text { Balancing intestinal microflora, protection against } \\
\text { traveller's diarrhoea, immune enhancement. }\end{array}$ & 9,20 \\
\hline B. lactis $\mathrm{Bb}-12$ & $\begin{array}{l}\text { Treatment of viral diarrhea including rotavirus diarrhea. } \\
\text { Alleviation of symptoms of food allergy. Balancing intestinal microflora }\end{array}$ & $1,8,9,13,15,20-22$ \\
\hline Lactobacillus gasseri (ADH) & Faecal enzyme reduction, survival in the intestinal tract. & 9,10 \\
\hline L. reuteri & Shortening of rotavirus diarrhea. Colonizing the intestinal tract. & $6,8,9$ \\
\hline S. boulardii & Prevention of antibiotic associated diarrhea. Treatment of $C$. difficile colitis. & $8,9,20,21$ \\
\hline
\end{tabular}


human gastrointestinal tract. Such an approach should clarify the apparent discrepancies in the published studies. The role of intestinal microflora in lactose utilisation should be clarified comparing the flora in subjects that tolerate no lactose or tolerate small amounts of lactose with the flora of subjects with no lactose malabsorption.

In conclusion, there is good scientific evidence for the alleviation of lactose intolerance symptoms by specific probiotic lactic acid bacteria. Many recent studies have been conducted blinded and placebo-controlled. However, the strain-specific lactase activities may vary over 100 -fold. Different products may have varying lactose contents and numbers of bacterial cells which, when released to the duodenum, vary in their lactase activity $(9,10,11)$. Thus, future studies should take these factors into consideration.

\section{Rotavirus diarrhoea}

A few probiotic strains have been reported effective in the treatment of rotavirus diarrhoea. The best studied strain, Lactobacillus rhamnosus strain GG (ATCC 53013) repeatedly reduces the duration of diarrhoea to about half in children with rotavirus diarrhoea in randomised double-blinded and placebo controlled studies $(1,6,8)$. Studies have been conducted using the strain in a fermented milk and in the freeze-dried form and the results have confirmed the efficacy of both formulations. This strain has also been reported to be effective in the treatment of watery diarrhoea in several studies in Europe and also in Asia and America. When different lactic acid bacteria were compared for their effects on the immune response to rotavirus in children with acute rotavirus gastroenteritis differences between various strains were observed (12). Serum antibodies to rotavirus, total number of immunoglobulin-secreting cells (ISC) and specific antibody-secreting cells (sASC) to rotavirus were measured at the acute stage and at convalescence. The treatment with Lactobacillus GG was associated with an enhancement of IgA sASC to rotavirus and serum IgA antibody level at convalescence. It was therefore suggested that certain strains of lactic acid bacteria promote systemic and local immune response to rotavirus, which may be of importance for protective immunity against reinfections (review of rotavirus diarrhoea: 1,6,9,13).

The effects of viable and heat-inactivated lactic acid bacteria have been compared in a blinded randomised clinical study (14). Lactobacillus GG administered as a viable preparation during acute rotavirus gastroenteritis resulted in a significant reduction in the duration of diarrhoea and an increase of rotavirus-specific IgA response at convalescence. The heat inactivated Lactobacillus GG was clinically as efficient, but the IgA response was not detected. This result suggests that viable and non-viable Lactobacillus GG can reduce the duration of rotavirus diarrhoea, but the viability of the strain may be critical in determining the capacity to induce immune stimulation (13). Also, in a study with different preparations of lactic acid bacteria using the recommended doses ( $1.25 \mathrm{~g}$ dose of freeze-dried preparation twice daily for 5 days) in the treatment of rotavirus diarrhoea it was shown that Lactobacillus GG (cell concentration $5 \times 10^{9} \mathrm{cfu} / \mathrm{g}$ ) was clinically effective whilst a preparation containing mixture of Streptococcus thermophilus $(95 \%)$ and Lactobacillus bulgaricus $(4 \%)$ or a L. rhamnosus $(1 \%)\left(2.8 \times 10^{8} \mathrm{cfu} / \mathrm{g}\right)$ or preparation containing $L$. rhamnosus $\left(2.2 \times 10^{8} \mathrm{cfu} / \mathrm{g}\right)$ did not have an effect on the duration of diarrhoea (12). It has also been reported that $L$. reuteri effectively shortened the duration of watery diarrhoea associated with rotavirus, but multicentre studies are not available for this strain $(6,8,9)$. Further strains studied in this area include Bifidobacterium lactis Bb-12 and Lactobacillus acidophilus LB1 with both strains studied by different research groups in different geographic areas $(13,15,16)$.
Shortening of the duration of rotavirus diarrhoea using Lactobacillus GG is perhaps the best-documented probiotic effect in human subjects. Most studies are randomised, placebocontrolled and double-blinded. The effect has been first documented in several studies around the world and thereafter in a multicentre study in Europe (13). There are also several studies using Bifidobacterium lactis $\mathrm{Bb}-12$ and two studies on Lactobacillus reuteri as well as studies using the heat-inactivated Lactobacillus acidophilus LB1 which reported shortening of the duration of rotavirus diarrhoea in children. As with other documented effects, it is important to remember that these reported studies are specific to the strains used and the strain properties should be carefully safeguarded in industrial use $(6,3,9,12,21)$.

\section{Antibiotic-associated diarrhoea}

Antibiotic-associated diarrhoea and gastrointestinal problems are an important area of probiotic application. Diarrhoea can occur as an imbalance of the normal intestinal microflora forming the protective barrier in our gastrointestinal tract. Reported controlled clinical studies indicate that antibioticassociated diarrhoea has been prevented by Lactobacillus GG strain in a yoghurt form using a dose of two cups of yoghurt daily with about $10^{7} \mathrm{cfu} / \mathrm{ml}$ in healthy volunteers (17) or as a freezedried product using doses varying from $10^{9}$ to $10^{10} \mathrm{cfu} /$ day in infants receiving antibiotics $(18,19)$. Supporting studies using Lactobacillus GG in the treatment of severe antibiotic-associated form of Clostiridium difficile colitis indicate some beneficial effects, but more controlled clinical studies in this specific area are still needed $(20,21)$.

Black et al. (22) reported a double-blinded study using 20 healthy volunteers treated with $500 \mathrm{mg}$ of ampicillin divided into two groups. Half of the volunteers received $4 \times 10^{9} \mathrm{cfu}$ live lyophilised Bifidobacterium lactis and L. acidophilus La5. The volunteers receiving lactic acid bacteria were recolonised faster than those receiving placebo and harboured higher counts than the controls. There are also good studies showing the efficacy of a probiotic yeast Saccharomyces boulardii in the treatment of antibiotic-associated diarrhoea and Clostridium difficile colitis, but the yeast is currently not used in foods $(8,20,21)$.

In conclusion, there is scientific evidence from wellcontrolled studies and different countries for the use of probiotic preparations in the prevention and treatment of antibioticassociated diarrhoea. However, the studies and the results are strain- and product-specific and cannot be extrapolated to other strains and products.

\section{Health benefits requiring further assessment in human studies}

\section{Alleviation of symptoms of food allergy}

Probiotics have been suggested to have potential in the management of food allergy (23-25). Studies with infants with atopic eczema have been given extensively hydrolysed whey formula or the same formula supplemented with the probiotic Lactobacillus rhamnosus strain GG (ATCC 53013). The infants with the probiotic supplementation had a significant improvement of clinical symptoms and alleviation of intestinal inflammation associated with food allergy. In a recent study the first clinical demonstration of specific probiotic strains modifying the markers related to allergic inflammation were reported for Bifidobacterium lactis Bb-12 and Lactobacillus rhamnosus strain GG (ATCC 53013) (25). The current data indicate that these probiotics may counteract inflammatory responses beyond the intestinal environment. It was suggested by Isolauri and coworkers ( 259 that the combined effects of these probiotics may 
guide the infant through the weaning period and offer new directions in the search of future foods for allergy treatment and prevention strategies. Further studies should be conducted to determine the interactions between probiotics, gut microflora and the immunological homeostasis of the host. The recent report on probiotics and prevention of atopic disease indicates that there is a great potential in this area of research in the future (26).

\section{Intestinal microecology - cancer}

A number of studies have focused on the effect of probiotics on intestinal microecology and cancer $(20,27,28)$. Lactobacillus acidophilus, Lactobacillus casei Shirota strain and Lactobacillus GG have been shown to have inhibitory properties on chemically induced tumours in animals $(1,6,8,9)$. Other studies indicate that specific strains of probiotic bacteria may be able downregulate intestinal microbial enzyme activities (8). This phenomenon may then decrease carcinogen activating microbial enzymes and has a beneficial effect in the colon, the urinary tract and the bladder. However, further studies, and especially human studies, are needed in this area $(27,28)$.

The reports on the benefits of oral administration of probiotic cultured milks and lactic acid bacteria on tumours have been connected with changes related to tumour induction and promotion $(27,28)$. The following mechanisms have been indicated in various studies relating lactic acid bacteria intake and cancer:

1) Alteration in intestinal microecology

(proposed beneficial microflora effects)

2) Altered intestinal metabolic activity

(altered conversion of precarcinogens to carcinogens)

3) Normalised intestinal permeability (decrease or delay

in the absorption and bioavailability of harmful

components and toxins)

4) Enhanced intestinal immunity (enhanced resistance to inflammation, chemicals and other factors)

5) Strengthened intestinal barrier mechanisms

(include all or some of the previous mechanisms 1-4)

At present, several studies have been reported on cancer and intestinal microecology related aspects, but the results have not been conclusive and human studies have been missing. The most convincing clinical reports have been published on Lactobacillus casei Shirota. There are several mechanistic studies on the effects of the strain reporting decreased urinary mutagen excretion. Other mechanisms have been assessed in both experimental animals and human subjects. Following the mechanistic studies on decreased urinary mutagen excretion, human clinical studies have been conducted using Lactobacillus casei Shirota. In one clinical study and another well-designed larger multicentre study the prophylactic effects of oral administration of Lactobacillus case $i$ Shirota on the recurrence of superficial bladder cancer have been reported in Japan $(29,30)$. Recently, a large Japanese case control study on the habitual intake of lactic acid bacteria and risk reduction of bladder cancer has been conducted in the specific setting of home delivery of the product. This study suggested that the habitual intake of the fermented milk with the strain reduces the risk of bladder cancer in the Japanese population (31). This result combined with the mechanistic work and human studies warrants further investigations also in other countries.

\section{Traveller's diarrhoea}

There are a few studies on the prevention of traveller's diarrhoea and these show positive outcome for Lactobacillus GG and a combination of Lactobacillus acidophilus LA5 with Bifidobacterium lactis $\mathrm{Bb}-12$ (for review see 8,9). There is also a large study on traveller's diarrhoea using Saccharomyces boulardii as
Table 3. Requirements for nutritional and clinical* studies of functional foods and probiotic foods with health claims.

- Each strain documented and tested independently

- Extrapolation of data from closely related strains not acceptable

- Well-defined probiotic strains, well-defined study products, well-defined study populations

- Double-blind, placebo controlled and randomised human studies

- Results confirmed by several independent research groups**

- Publication in peer-reviewed journals

* Clinical studies conducted according to the good clinical practice in human subjects

** Clinical results should be confirmed by several independent, and at least two research groups

an agent with encouraging results, but the study needs to be repeated by other groups $(20,32)$. Most of these studies are double-blinded and placebo-controlled and show indications of beneficial effects, and there are some studies with no reported effects, but the information on large good human studies using defined strains on traveller's diarrhoea is still largely lacking. The current data on traveller's diarrhoea does not show scientifically proven effects for any strains used. Thus, further human studies with known bacterial aetiology diarrhoea should be conducted to verify the earlier results.

\section{Helicobacter pylori}

Specific strains of lactic acid bacteria have been reported to inhibit many intestinal pathogens including Helicobacter pylori (33). Lactic acid bacteria are often able to survive the acidic gastric conditions and therefore it has been proposed that they may have a beneficial influence during the eradication of Helicobacter pylori, which is involved in the process of gastric ulcer development. It has been reported that both the inhibitory substances and the specific strains and their supernatants may influence the survival of Helicobacter, and studies have been conducted especially with Lactobacillus johnsonii strain LA1 (34). It has been shown that there is good in vitro inhibition and that the supernatant of the strain has a positive effect when consumed during Helicobacter eradication therapy (34). In another study Lactobacillus acidophilus yoghurt did not have an effect on Helicobacter eradication (35). A recent study shows that the inactivated L. acidophilus could be effective in increasing eradication rates of a standard anti- $H$. pylori therapy (36). However, it is clear that more controlled human studies conducted in different populations are needed to assess this effect.

\section{Probiotics - cholesterol lowering}

In spite of the large number of studies and the great interest in the area, there are currently no consistent studies that relate to the lowering of cholesterol by the use of probiotics or probiotic products. Thus, this area remains to be further assessed in the future $(7,8)$.

\section{Future challenges}

Relatively few comprehensive studies exist on the development and composition of human intestinal microflora which forms the basis for all intervention studies. This area has been reviewed by Benno and Mitsuoka (37). However, recent progress in the specific design of probiotic microbes (38) and molecular analysis of human intestinal microflora assessing host microbe relationships (39) have shown that there is a good place for therapeutic management or manipulation of the intestinal microflora and management of microflora-related diseases. 
There is a need to further develop and conduct clinical studies with probiotic bacteria since only a few of the claimed effects are hypothesis-based and backed by good clinical studies.

It is important to make sure that the nutritional and human studies are well defined and planned. Each strain and product should be documented and tested independently, since extrapolation of data from closely related strains is not acceptable. Table 3 contains suggestions for scientific documentation of health effects in human studies. There is also a need to assess the importance of viability of probiotics for some of the proposed study areas. Non-viable preparations have documented beneficial effects for specific use areas $(14,16,36)$ and this form of probiotic product may prove to be important in areas of the world where product storage and transport conditions for the mostly very temperature and humidity sensitive viable preparations are not available.

Protocols for human nutrition studies need to be developed for probiotics and functional foods. In some cases even postmarketing surveillance studies on intakes and long-term effects are desirable. Such studies have been used also for the safety assessment of current probiotics.

The design of clinical studies used in pharmaceutical development should serve as a reference point, but also specific protocols and specific criteria relevant to functional foods may be needed. It is necessary to identify specific target groups of individuals who may present higher/lower susceptibilities to potential adverse effects. It is also important to clarify the longterm consequences of the interactions between functional food components and functions in the body and the interactions between components must be carefully monitored (Table 3 ). This will enable further beneficial health effects to be scientifically proven for the benefit of the consumers and of probiotic development.

\section{Conclusions}

In conclusion, the best-documented areas of probiotic health effects for humans include shortening the duration of rotavirus diarrhoea, alleviating the symptoms and reducing the risk of antibiotic associated diarrhoea and alleviation of symptoms of lactose intolerance. There are several interesting effects that require further rigorous studies before they can be considered scientifically proven. The current probiotic research has shown that there are possibilities for the increased well-being and therapeutic manipulation of intestinal microflora to promote health. Future studies will provide the information for both food and potentially pharmaceutical uses of probiotic microbes in the future.

\section{REFERENCES}

1. Salminen S, Bouley MC, Boutron-Rualt MC, Cummings J, Franck A Gibson G, Isolauri E, Moreau M-C, Roberfroid M, Rowland I: Functional food science and gastrointestinal physiology and function. $\mathrm{Br} \mathrm{J}$ Nutr 1998;Suppl 1;S147-S171

2. Diplock AT, Aggett P, Ashwell M, Bornet F, Fern E, Roberfroid M Scientific concepts of functional foods in Europe: consensus document. $\mathrm{Br}$ J Nutr 1999:81:Suppl 1:S1-S27.

3. Tuomola E, Crittenden R, Playne M, Isolauri E, Salminen S: Quality assurance criteria for probiotic bacteria. Am J Clin Nutr 2001;73: 3935-85.

4. Salminen S, Ouwehand A, Benno Y, Lee Y-K: Probiotics: how should they be defined? Trends in Food Science and Technology 1999;10:1-4.

5. Sandström B. Quality criteria in human experimental nutrition research. Eur J Clin Nutr 1995;49:315-22.

6. De Roos N, Katan M: Effects of probiotic bacteria on diarrhoea, lipid metabolism, and carcinogenesis: a review of papers published between 1988 and 1998. Am J Clin Nutr 2000; 71:405-11.

7. Pathmakanthan S, Meance S, Edwards CA: Probiotics: A review of human studies to date and methodological aspects. Micr Ecol Health Dis. 2000:Suppl 2:10-30.

8. McFarland L. A review of the evidence of health claims for biotherapeutic agents. Micr Ecol Health Dis 2000:12:65-76.

9. Fondén R, Mogensen G, Tanaka R, Salminen S: Culture-containing dairy products - effect on intestinal microflora, human nutrition and health - current knowledge and future perspectives. Bull Internl Dairy Fed 2000:352. 10. de Vrese, Stegelmann A, Richter B, Fenselau S, Laue C, Schrezenmeir J: Probiotics - compensation for lactase insufficiency. Am J Clin Nutr 2001;73:S421-9S

11. Sanders ME, Walker DC, Walker KM, Aoyama K, Klaenhammer TR Performance of commercial cultures in fluid milk applications. J Dairy Sci 1996;79:943-55.

12. Majamaa $H$, Isolauri $E$, Saxelin $M$, Vesikari T: Lactic acid bacteria in the treatment of acute rotavirus gastroenteritis. J Pediatr Gastroenterol Nutr 1995;20:333-8.

13. Guandalini S, Pensabene L, Zikri MA, Dias J. et al.: Lactobacillus GG administered in oral rehydration solution to children with acute diarrhoea: a multicenter European trial. J Ped Gastroenterol Nutr 2000:30:54-60.

14. Kaila M, Isolauri E, Saxelin M, Arvilommi H, Vesikari T: Viable versus inactivated Lactobacillus strain GG in acute rotavirus diarrhoea. Arch Dis Child 1995:72:51-3.

15. Saavedra JM, Bauman NA, Oung I, Perman JA, Yolken RH: Feeding of Bifidobacterium bifidum and Streptococcus thermophilus to infants in hospital for prevention of diarrhoea and shedding of rotavirus. The Lancet 1994; 344:1046-9.

16. Simakachorn N, Pichaipat V, Ritchipornpaisarn, Kongkaew C, Tongpradit P, Varavithya W: Clinical evaluation of the addition of lyophilized, heatkilled Lactobacillus acidophilus LB to oral rehydration therapy in the treatment of acute diarrhoea in children. Ped Gastroenterol Nutr 2000 30:68-72.

17. Siitonen $S$, Vapaatalo $H$, Salminen $S$, Gordin A, Saxelin M, Wikberg R, Kirkkola A-M: Effect of Lactobacillus GG yoghurt in prevention of antibiotic associated diarrhoea. Ann Med 1990, 22:57-60.

18. Arvola T, Laiho K, Torkkeli S, Mykkänen H, Salminen S, Maunula I Isolauri E: Prophylactic Lactobacillus GG reduces antibiotic-associated diarrhoea in children with respiratory infections: a randomized study. Pediatrics 1999;104:64.

19. Vanderhoof J, Whitney D, Antonson D, Hanner T, Lupo J, Young R. Lactobacillus $\mathrm{GG}$ in the prevention of antibiotic associated diarrhoea in children. J Pediatr 1999:135:564-8.

20. Marteau P, de Vrese M, Cellier C, Schrezenmeir J: Protection from gastrointestinal diseases with the use of probiotics. Am J Clin Nutr 2001; 73:430S-6S

21. Pochapin M: The effect of probiotics on Clostridium difficile diarrhoea. Am J Gastroenterol 2000;95:11S-13S.

22. Black FT, Einarsson K., Lidbeck A, Orrhage K, Nord C: Effects of lactic acid producing bacteria on the human intestinal microflora during ampicillin treatment. Scand J Infect Dis 1991;23:247-54

23. Isolauri E, Arvola T, Sütas Y, Moilanen E, Salminen S: Probiotics in the management of atopic eczema. Clin Experiml Allergy 2000:30:1605-10.

24. Kirjavainen P, Apostolou E, Salminen S, Isolauri E: New approaches of probiotics - a novel approach in the management of food allergy. Allergy 1999;54:909-15.

25. Kalliomäki M, Kirjavainen P, Eerola E, Kero P, Salminen S, Isolauri E: Distinct patterns of neonatal gut microflora in infants developing or not developing atopy. Submitted to J Allergy and Clin Immunol. 2001;107:129-34

26. Kalliomäki M, Salminen S, Arvilommi H, Kero P, Koskinen P, Isolauri E Probiotics in the prevention of atopic diseases: a randomised placebocontrolled trial. The Lancet 2001;357:1076-9.

27. Wollowski I, Rechkemmer G, Pool-Zobel B: Protective role of probiotics and prebiotics in colon cancer. Am J Clin Nutr 2001;73:451S-6S

28. Burns A, Rowland I:Anti-carcinogenicity of probiotics and prebiotics. Curr Issues Intesti Microbiol 2000;1:13-24.

29. Aso Y, Akazan H: Prophylactic effect of a Lactobacillus casei preparation on the recurrence of superficial bladder cancer. Urol Int 1992;49:125-9.

30. Aso Y, Akaza H, Kotake T, Tsukamoto T, Imai K, Naito S : Preventive effect of a Lactobacillus casei preparation on the recurrence of superficial bladder cancer in a double-blind trial. Eur Urol 1995;27:104-9.

31. Ohashi Y. Case Control study for bladder cancer prevention: habitual intake of lactic acid bacteria prevents occurrence of bladder cancer. Proceedings of 2nd International Congress on Probiotics, Guadalajara, Mexico, 2000.

32. von $\mathrm{H}$, Holst $\mathrm{H}$, Grobara P, Wiedermann G: Prophylaxe des Reisediarrhöe mit Saccharomyces boulardii. (Prevention of traveller's diarrhoea by Saccharomyces boulardii). Fortschritte der Medizin 1993;111:153-6. ????

33. Midolo P, Lambert J, Hull R, Luo F, Grayson M: In vitro inhibition of Helicobacter pylori NCTC 11637 by organic acids and lactic acid bacteria J Appl Bacteriol 1995;79:475-9.

34. Mitchetti P, Dorta G, Wiesel P, Brassart D, Wedu E, Herman M, Felley C, Porta N, Rouvet M, Blum A, Corthesy-Theulan I: Effect of whey based supernatant of Lactobacillus acidophilus (johnsonii) La 1 on Helicobacter pylori infection in humans. Digestion 1999:60:203-9.

35. Bazzoli $\mathrm{F}$, Zagari $\mathrm{R}$, Fossi $\mathrm{S}$ et al.: In vivo Helicobacter pylori clearance failure with Lactobacillus acidophilus. Gastroenterology 1992;102:A38.

36. Canducci $F$ et al.:A lyophilized and inactivated culture of Lactobacillus acidophilus increases Helicobacter pylori eradication rates" by Alimen Pharmacol Ther 2000;14:1625-9.

37. Benno Y, Mitsuoka T: Development of intestinal microflora in humans and adults. Bifidobacteria Microflora 1986;5:13-25.

37. Steidler L, Hans W, Schotte L, Neirynck S, Obermeier F, Falk W, Fiers W, Remaut E: Treatment of murine colitis by Lactococcus lactis secreting interleukin-10. Science 2000;289: 1352-3.

38. Hooper L, Wong M, Thelin A, Hansson L, Falk P, Gordon J: Molecular analysis of commensal host-microbial relationships in the intestine. Science 2001;291:881-4 